\title{
Uncontrolled diabetes mellitus: A risk factor for post COVID fibrosis
}

\author{
Parul Mrigpuri, Sonal Sonal, Sonam Spalgais, Nitin Goel, Balakrishnan Menon, Raj Kumar \\ Department Pulmonary Medicine, Vallabhbhai Patel Chest Institute, University of New Delhi, India
}

\section{Dear Editor,}

The Corona virus disease (COVID-19) caused by severe acute respiratory syndrome coronavirus 2 (SARS-CoV-2) emerged in the Wuhan province of china in December 2019. COVID-19 spread to the world in a short time and was declared as public health emergency of international concern by World Health Organization. The disease has been found to be associated with various systemic and pulmonary sequelae pulmonary fibrosis being one of them. We came across three patients of uncontrolled diabetes who have developed pulmonary fibrosis following COVID-19 infection. None of the patients had any history of prior respiratory illness. All were above 60 years of age and had a poor glycemic control as reflected by the HBA1C values at admission. They were being treated with oral hypoglycemic agents but after admission they were managed with regular insulin. The time to development of fibrosis varied between 4-6 weeks. Two patients were discharged on domiciliary oxygen therapy while one developed secondary infection and succumbed to the disease. SARS and Middle East respiratory syndrome corona virus infections has

Correspondence: Dr Parul Mrigpuri, Room No. 22, OPD Block, Assistant Professor, Department of Pulmonary Medicine, Vallabhbhai Patel Chest Institute, New Delhi 110007, India.

E-mail: parul57_mrigpuri@yahoo.com

Key words: Pulmonary fibrosis; risk factors; infection.

Author contributions: All authors have contributed to this manuscript, have approved the final version and agreed to be accountable for all aspects of work.

Ethics approval and consent to participate: Not applicable.

Consent for publication: Written informed consent from the patients was obtained.

Availability of data and material: Not applicable.

Conflict of interest: The authors declare that they have no competing interests.

Received for publication: 14 September 2020.

Accepted for publication: 25 November 2020.

${ }^{\circ}$ Copyright: the Author(s), 2021

Licensee PAGEPress, Italy

Monaldi Archives for Chest Disease 2021; 91:1607

doi: 10.4081/monaldi.2021.1607

This article is distributed under the terms of the Creative Commons Attribution Noncommercial License (by-nc 4.0) which permits any noncommercial use, distribution, and reproduction in any medium, provided the original author(s) and source are credited. been found to be associated with severity and mortality in diabetic patients and a substantial number of patients infected with these viruses developed fibrotic lung disease $[1,2]$. Although glucose metabolism has not been studied extensively in patients with COVID-19, diabetics with SARS-CoV-2 infection has greater release of hyperglycemic hormones resulting in higher blood glucose levels and disturbed glucose variability. Some studies found death from COVID-19 to be strongly associated with uncontrolled diabetes; however, others showed no association of long- term glucose control with death [2].

As the pandemic is progressing various cardiac, neurological, renal, pulmonary, and psychiatric sequelae of the infection are being reported. Long term pulmonary complications of COVID19 mainly include chronic cough, bronchiectasis, pulmonary fibrosis, and pulmonary vascular complications [3]. Although, the prevalence of post COVID-19 fibrosis is unknown, but initial analysis of COVID-19 recovered cases has been suggestive of a considerable number of recovered cases developing fibrotic changes in lungs [4]. Pulmonary fibrosis is one of the most debilitating sequelae of the infection. Fibrosis happens because of abnormal wound healing process. Advanced age, severity of illness, length of intensive care unit (ICU) stays and mechanical ventilation, smoking and chronic alcoholism have been listed as the risk factors for pulmonary fibrosis in COVID-19 infection [5]. Association of pulmonary fibrosis with duration of acute respiratory distress syndrome (ARDS) has been evaluated in autopsy studies showing more patients developing fibrosis with increased duration of ARDS [1]. There is a possibility that uncontrolled diabetes can be an additional risk factor for the development of fibrosis in COVID-19 recovered cases. All three patients we encountered were non-smoker, non-alcoholic elderly males with uncontrolled diabetes but no prior history of chronic lung disease. They had moderate disease and did not require mechanical ventilation (Figure 1). Although, fibrosis is commonly seen among people with severe illness and those requiring mechanical ventilation, but
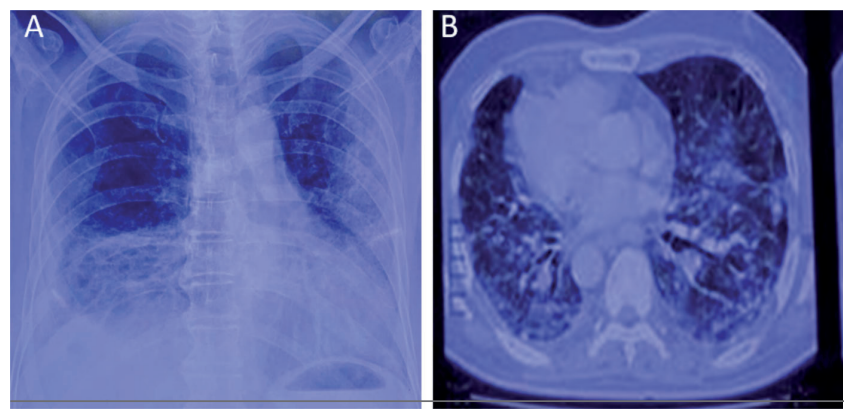

Figure 1. Chest $x$-ray (A) showing bilateral heterogenous opacities predominantly involving the lower zones and Computed tomography scan (B) showing development of interlobular septal thickening and reticulations. 
in our scenario, all the three patients had moderate illness without the need of ICU and mechanical ventilation. Inflammatory mediators along with virus induced cell injury results in lung damage in COVID-19 [5]. Diabetes is a chronic inflammatory condition and old age is also associated with abnormal T-cell and B-cell function and excess inflammation [2]. Thus, diabetes mellitus along with older age, might result in prolonged inflammatory response, causing pulmonary fibrosis. Hence, it is emphasized that COVID-19 patients with uncontrolled diabetes may be more prone to the development of pulmonary fibrosis. However, studies are needed in this context.

\section{References}

1. George PM, Wells AU, Jenkins RG. Pulmonary fibrosis and COVID-19: the potential role for antifibrotic therapy. Lancet Respir Med 2020;8:807-15.

2. Hussain A, Bhowmik B, do Vale Moreira NC. COVID-19 and diabetes: Knowledge in progress. Diabetes Res Clin Pract 2020;162:108142.

3. Fraser E. Long term respiratory complications of Covid-19. BMJ 2020;370:m3001.

4. Vasarmidi E, Tsitoura E, Spandidos DA, et al. Pulmonary fibrosis in the aftermath of the COVID-19 era (Review). Exp Ther Med 2020;20:2557-60.

5. Ojo AS, Balogun SA, Williams OT, Ojo OS. Pulmonary fibrosis in COVID-19 survivors: Predictive factors and risk reduction strategies. Pulm Med 2020;2020:1-10. 